Journal of Advanced Research in Materials Science

Journal homepage: www.akademiabaru.com/arms.html ISSN: 2289-7992

\title{
Magnetic Nanofluids for Heat Transfer Enhancement Inside Straight Channels
}

\author{
Mohammed Raad Abdulwahab ${ }^{1}$, Nor Azwadi Che Sidik ${ }^{1,}{ }^{*}$, Siti Nurul Akmal Yusof ${ }^{1}$, Muhammad \\ Mahmud Jamil ${ }^{2}$ \\ 1 Malaysia - Japan International Institute of Technology (MJIT), University Teknologi Malaysia,Jalan Sultan Yahya Petra,54100 Kuala Lumpur, \\ Malaysia \\ 2 Department of Mechanical Engineering, Nigerian Defence Academy, Kaduna, PMB 2109, Kaduna, Nigeria
}

\section{ABSTRACT}

A numerical study for investigating the fluid flow and heat transfer enhancement inside square, circular and triangular straight channels with hydraulic diameter of $0.01 \mathrm{~m}$ using magnetic nanofluid (Fe304 suspended in water) as a base fluid under constant heat flux subjected around the geometries walls has been presented to determine the effects of nanoparticle volume fraction and flow rate on the convective heat transfer and friction factor of nanofluid without the influence of magnetic field. The nanofluid consists of Fe304 magnetic nanoparticles with average diameter of $36 \mathrm{~nm}$ suspended in water with a different volume fraction which were $0.2,0.4$, and $0.6 \%$. The study was conducted at steady state, turbulent forced convection with Reynolds number $(5000$ $\leq \operatorname{Re} \leq 20000)$, three-dimensional flow, and single-phase approach. Certain boundary conditions and assumptions to solve the governing equations have been implemented using finite volume method. CFD software involving GAMBIT and FLUENT were employed to perform the investigation numerically. The results revealed that as Reynolds number increased, the heat transfer rate was also increased for all the geometries but it is better in circular tube case. While in the case of using pure water as a coolant, the heat transfer rate is lower than that the case of using nanofluid with respect to the flow inside all the geometries. In addition, as Reynolds number increase, friction factor decreases for all cases and it is large in case of square duct. New correlations were proposed to predict Nusselt number and friction factor based on the dimension less numbers which are valid for the three geometries.

\section{Keywords:}

Turbulent flow; straight rectangular channel; nanofluids

Copyright @ 2020 PENERBIT AKADEMIA BARU - All rights reserved

\section{Introduction}

Experimental studies on heat transfer enhancement in channels and tubes have been performed in the past decades to improve the thermal systems techniques [1-9]. One of the most effective method to enhance the heat transfers in channels and tubes is to use nanofluid. Nanofluids are engineered colloids made of a base fluid and nanoparticles. The term "Nanofluid" was first used by Choi in 1995 [10]. He defined them as fluids containing particles of sizes below $100 \mathrm{~nm}$. Nanofluids can be classified in different aspects: Base fluid, particle material, particle size, particle concentration, dispersant and $\mathrm{pH}$-value of the nanofluid. In some cases, dispersants are used to stabilize the particles

\footnotetext{
* Corresponding author.

E-mail address: azwadi@utm.my

https://doi.org/10.37934/arms.68.1.819
} 
in the nanofluid and prevent the particles from sedimenting. Nanoparticles are particles that are between 1 and $100 \mathrm{~nm}$ in diameter. Nanofluids typically employ metal or metal oxide nanoparticles, such as copper and alumina, and the base fluid is usually a conductive fluid, such as water or ethylene glycol [11-12]. Nanofluids are studied because of their heat transfer properties: they enhance the thermal conductivity and convective properties over the properties of the base fluid [10,13-16].

Rostamani et al., [1] were numerically study the forced convection of turbulent nanofluid flow inside a straight square duct (two-dimension study) under constant heat flux using different type of nanofluid (water as a base fluid). From the results they observed that the wall shear stress and heat transfer rates increase as nanoparticle volume fraction increasing and the effect of $\mathrm{CuO}$ nanoparticles to improve Nusselt number is better than $\mathrm{Al}_{2} \mathrm{O}_{3}$ and $\mathrm{SiO}_{2}$. Turbulent flow and heat transfer of three different nanofluids $\left(\mathrm{CuO}, \mathrm{Al}_{2} \mathrm{O}_{3}\right.$ and $\left.\mathrm{SiO}_{2}\right)$ in an ethylene glycol and water mixture flowing under constant heat flux condition of 50 were numerically analyzed by Namburu et al., [17]. For the same concentration of $\mathrm{CuO}, \mathrm{Al}_{2} \mathrm{O}_{3}$ and $\mathrm{SiO}_{2}$ nanofluids, at a particular Reynolds number, $\mathrm{CuO}$ nanofluids had higher heat transfer performance followed by $\mathrm{Al}_{2} \mathrm{O}_{3}$ and $\mathrm{SiO}_{2}$.

Xuan and $\mathrm{Li}$ [2] investigated experimentally the convective heat transfer and flow characteristics for $\mathrm{Cu}$-water nanofluid flowing through a straight tube with a constant heat flux under laminar and turbulent flow conditions. The results of the experiment showed that the suspended nanoparticles remarkably enhanced the heat transfer performance of the conventional base fluid and their friction factor coincided well with that of the water. Furthermore, they also proposed new convective heat transfer correlations for prediction of the heat transfer coefficients of the nanofluid for both laminar and turbulent flow conditions.

Tsai et al., [3] investigated gold-deionized water nanofluid flowing in a conventional heat pipe with a diameter of $6 \mathrm{~mm}$ and a length of $170 \mathrm{~mm}$. Their data showed that the nanofluid causes a significant reduction in the thermal resistance of the heat pipe compared with deionized water at given concentrations. Forced convection heat transfer with turbulent nanofluid flow inside tube was experimentally studied by Sundar et al., [7]. The nanofluid used was magnetic nanoparticles suspension in water with nanoparticle volume concentrations from 0 to $0.6 \%$ and range of Reynolds's number from 3000 to 22000 . New correlation was proposed to estimate Nusselt number and friction factor. The results raveled that the heat transfer is enhanced by $30.93 \%$.

In many practical applications, the Reynolds number based on the tubes is usually very high, and the flow regime is turbulent. For practical computations, turbulent flows are commonly computed using the Navier-Stokes equations in an averaged form. The averaging process gives rise to new unknown terms representing the transport of mean momentum by fluctuating quantities. These undetermined terms are the Reynolds stresses and they lead to the well-known closure problem for turbulent flow computations. In order to determine these quantities, turbulence models are required which consist of a set of algebraic or differential equations. Several one-point turbulence models have been developed which can be used in CFD to simulate the turbulent flow. However, most of them are just good under some specific flow situations. A proper choice of turbulence models is important and can have a large effect on the accuracy of the simulations. According to the Changcharoen and Eisma-ard [18] the data obtained from the RNG $k-\varepsilon$ turbulence model are significantly overpredicted with respect to the measured data while those achieved from the SST $k-\omega$ turbulence model are found to be comparable for the entire region considered. This indicates that the $k-\varepsilon$ turbulence model is more reliable for the present case. In some of the previous works, the $k-\varepsilon$ turbulence model has been recommended for predicting the heat transfer and fluid flow in the channel rather than other models including the RNG $k-\varepsilon$ turbulence model, SST $k-\varepsilon$ turbulence model, and $k-\omega$ turbulence model [19]. A complete search of the literature revealed that there is no previous research focus on study the behavior of turbulent flow using a magnetic 
nanofluid $\left(\mathrm{Fe}_{3} \mathrm{O}_{4} /\right.$ water) without the influence of magnetic field in inside the different geometries square, circular and triangular channels.

The purpose of this study is to investigate convection heat transfer phenomenon and pressure drop in different geometries (square, circular and triangular channels) using magnetic nanofluid $\left(\mathrm{Fe}_{3} \mathrm{O}_{4} /\right.$ water) without the influence of magnetic field with different concentration of nanoparticles in a fully developed in compressible turbulent flow inside channels. This may be realistic as nanoparticles are much smaller than micron-sized particles and the relative velocity decreases as the particle size decreases. The resultant mixture may be considered as a conventional single-phase fluid. The standard $k-\varepsilon$ model is used to predict the kinetic energy and its dissipation rate in the turbulent flow. All the thermophysical properties of nanofluids are temperature-dependent.

\section{Methodology}

\subsection{Descriptions of Problem and Conservation Equations}

The 3-dimensional channel used in the simulations is square channel, circular channel and triangular channel. Consider a straight duct of uniform square cross section. Let $x$ denote the axial direction while $y$ and $z$ denote the coordinates of the cross section. The velocities corresponding to these coordinate directions are respectively. A circular tube is considered with $y$ and $r$ as a cross section coordinates and $x$ as an axial direction. A triangular duct is considered with $y$ and $z$ as a cross section coordinates and as an axial coordinate. The channel dimension and the other characteristics of the geometry are listed in the Table 1. Figure 1 shows the parameters of the three geometries. The CFD code used for this study was FLUENT solver which uses an element-based on finite volume method. In the current investigation, the CFD technique could be divided into the general steps which include the preprocessing stage, model setting and solving, and the final step is post processing. The computational mesh was generated by using Gambit software, then the numerical model, initial boundary conditions, assumptions, and other numerical values are defined in order to determine the heat transfer enhancement and other results when the solutions converged resulting from Fluent iterative process for all governing equations were lower than $10^{-6}$. These equations involved in steady and incompressible turbulent flow through straight channel include the continuity, momentum and energy equations.

Table 1

Geometrical parameters for square, circular and triangular channel

\begin{tabular}{lll}
\hline Channel type & Parameters & Range (m) \\
\hline \multirow{4}{*}{ Square } & Hydraulic Diameter of Duct $D_{H}$ & 0.01 \\
& Height (h) & 0.01 \\
& Width (W) & 0.01 \\
Circular & Length (L) & 1.80 \\
& Diameter (D) & 0.010 \\
& Radius ( $)$ & 0.005 \\
Triangular & Length (L) & 1.0 \\
& Edge Length (a) & 0.017 \\
& Height of triangle (h) & 0.0147224 \\
\hline
\end{tabular}




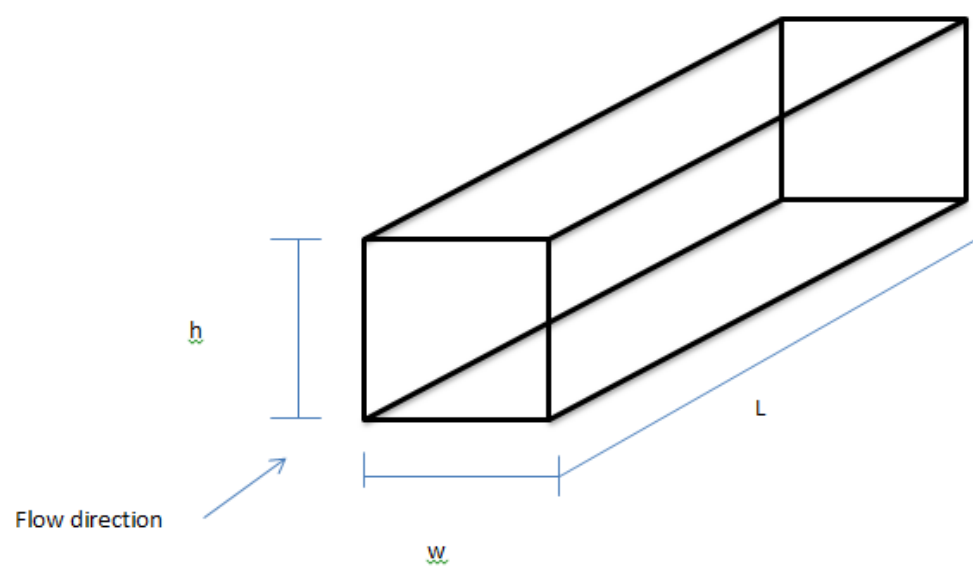

(a)

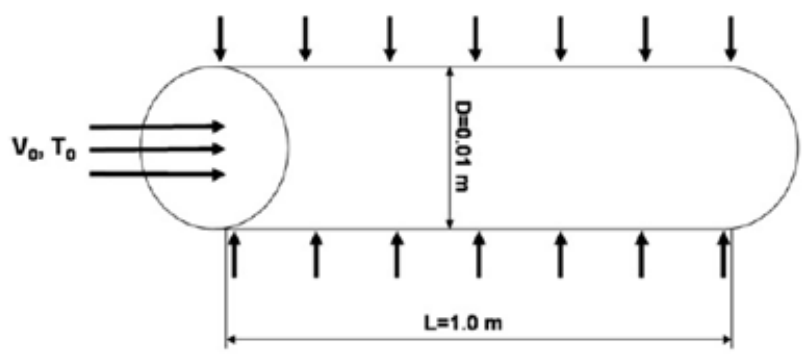

(b)

$q=50000 w / m^{2}$

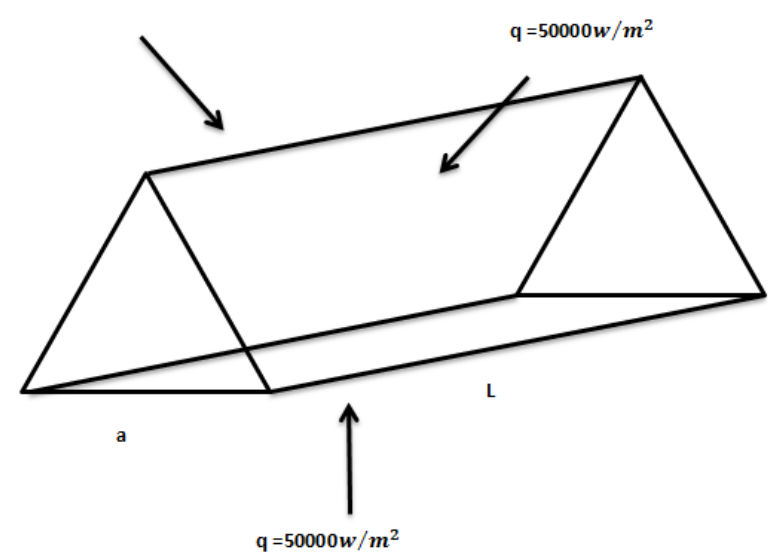

(c)

Fig. 1. Geometrical parameters for all channels

The following conservation equations are then obtained for steady turbulent flows:

Continuity equation:

$\frac{\partial \bar{u}}{\partial x}+\frac{\partial \bar{v}}{\partial y}+\frac{\partial \bar{w}}{\partial z}=0$

$\rho\left(\bar{u} \frac{\partial \bar{u}}{\partial x}+\bar{v} \frac{\partial \bar{u}}{\partial y}+\bar{w} \frac{\partial \bar{u}}{\partial z}\right)=-\frac{\partial \bar{\rho}}{\partial x}+\mu \nabla^{2} \bar{u}-\frac{\partial}{\partial x} \rho \overline{u^{12}}-\frac{\partial}{\partial y} \rho \overline{u^{\prime} v^{\prime}}-\frac{\partial}{\partial z} \rho \overline{u^{\prime} w^{\prime}}$ 


$$
\begin{aligned}
& \rho\left(\bar{u} \frac{\partial \bar{v}}{\partial x}+\bar{v} \frac{\partial \bar{v}}{\partial y}+\bar{w} \frac{\partial \bar{v}}{\partial z}\right)=-\frac{\partial \bar{\rho}}{\partial y}+\mu \nabla^{2} \bar{v}-\frac{\partial}{\partial x} \rho \overline{u^{\prime} v^{\prime}}-\frac{\partial}{\partial y} \rho \overline{v^{\prime 2}}-\frac{\partial}{\partial z} \rho \overline{v^{\prime} w^{\prime}} \\
& \rho\left(\bar{u} \frac{\partial \bar{w}}{\partial x}+\bar{v} \frac{\partial \bar{w}}{\partial y}+\bar{w} \frac{\partial \bar{w}}{\partial z}\right)=-\frac{\partial \bar{\rho}}{\partial z}+\mu \nabla^{2} \bar{w}-\frac{\partial}{\partial x} \rho \overline{u^{\prime} w^{\prime}}-\frac{\partial}{\partial y} \rho \overline{v^{\prime} w^{\prime}}-\frac{\partial}{\partial z} \rho \overline{w^{12}} \\
& \rho c_{p}\left(\bar{u} \frac{\partial \dot{t}}{\partial x}+\bar{v} \frac{\partial \dot{t}}{\partial y}+\bar{w} \frac{\partial \dot{t}}{\partial z}\right)=k \nabla^{2} t-\frac{\partial}{\partial x} \rho c_{p} \overline{u^{\prime} t^{\prime}}-\frac{\partial}{\partial y} \rho c_{p} \overline{v^{\prime} t^{\prime}}-\frac{\partial}{\partial z} \rho c_{p} \overline{w^{\prime} t^{\prime}}
\end{aligned}
$$

where

$$
\nabla^{2}=\frac{\partial^{2}}{\partial x^{2}}+\frac{\partial^{2}}{\partial y^{2}}+\frac{\partial^{2}}{\partial z^{2}}
$$

The governing equations for the circular tube are same as the previous equations just the rectangular coordinates are replaced to cylindrical coordinates.

\subsection{Boundary Conditions}

The governing equations of the incoming fluid flow are non-linear and coupled with partial differential equations and it is subjected to the boundary conditions. The solution domain of the problem under study considered three-dimensions, straight channel flow with square, circular and triangular cross sections, enclosed by all the geometry surfaces, inlet, outlet and walls. It is assumed that the incoming flow through the total length is steady forced turbulent at ambient temperature $\left(T_{i n}=293 K\right)$, and pressure with uniform velocity $\left(u_{i n}=u_{i} ; u_{j}=0\right)$ and constant heat flux for

upper and bottom wall of $\left(q^{\prime \prime}=50000 \frac{\mathrm{w}}{\mathrm{m}^{2}}\right)$, for the square cross section channel the heat flux is subjected on channel upper, lower, lift and right side walls, the temperature is $\left(T_{w}=293 \mathrm{~K}\right)$, for circular tube cross section the heat flux is subjected around the geometry and for the triangular cross section channel the heat flux is subjected to the three walls of the geometry. The flow enters the test sections with fully developed profile. Different fluid velocities enter the geometry and they vary to ensure Reynolds numbers in the range of 5000-22000. Outflow boundary condition has been implemented for the outlet section.

The boundary values for the turbulent quantities near the wall are specified with the standard wall-treatment method. The values of $\mathrm{C} \mu=0.009, \mathrm{C} 1 \varepsilon=1.44, \mathrm{C} 2 \varepsilon=1.92, \sigma_{\mathrm{k}}=1, \sigma_{\varepsilon}=1.3$ and $\operatorname{Pr}=0.09$ are chosen to be the empirical constants in the turbulence transport equations [20]. Eqs (7) to (9) are used to calculate the turbulent intensity $(I)$, turbulent kinetic energy $(k)$ and turbulent dissipation rate $(\varepsilon)$ at the inlet section of the channels [21].

$$
\begin{aligned}
& I=0.16 \operatorname{Re}^{\frac{-1}{8}} \\
& K=\frac{3}{2}\left(I \times U_{i n}\right)^{2}
\end{aligned}
$$




$$
\varepsilon=C_{\mu}^{0.75} \frac{K^{1.5}}{0.1 h}
$$

\subsection{Dimensionless Parameter}

The Nusselt numbers, the Reynolds number, the Darcy friction factor, the performance evaluation criteria and pumping power in case of the present study were calculated respectively, as follows:

$$
\begin{aligned}
& N u=\frac{\boldsymbol{h} d_{h}}{k} \\
& R e=\frac{\rho u_{m} d_{h}}{\mu} \\
& f=\frac{2 \Delta P d_{h}}{L \rho u_{m}^{2}}
\end{aligned}
$$

where the $\Delta P$ is pressure difference between inlet and outlet:

$\Delta P=P_{\text {ave,inlet }}-P_{\text {ave,outlet }}$

Hence, $P_{\text {ave, inlet }}, P_{\text {ave,outlet }}$ are the inlet and outlet pressures, respectively.

The Darcy friction factor determines the pump or fan power requirements and it can be calculated by using Fanning friction factor as follows [22]:

$f=4 C_{f}$

Fanning friction factor is defined as follows [23]:

$$
C_{f}=\frac{2 \tau_{w}}{\rho u_{m}^{2}}
$$

where, $\tau_{w}$ is the wall shear stress.

Nusselt numbers correlations are a classical expression for computing the local Nusselt number for fully developed turbulent flow in both hydrodynamically and thermally profile in smooth channels. The Pak and Cho equation [24] is expressed as

$$
N u=0.021 R e^{0 . .80} \operatorname{Pr}^{0.5}
$$

This equation has been confirmed experimentally for the range of conditions:

I. The value of Reynolds numbers is $10^{4} \leq \operatorname{Re} \leq 10^{5}$

II. The Prandtl numbers are in the range of $6.54 \leq \operatorname{Pr} \leq 12.33$

The Gnielinski correlation applies for both uniform surface heat flux and temperature for smooth tubes with fully developed flow condition of the form [25]:

$$
N u=0.012\left(R e^{0.87}-280\right) P r^{0.4}
$$


It is valid for Prandtl and Reynolds numbers in the ranges of $1.5 \leq \operatorname{Pr} \leq 500$ and $3 \times 10^{3} \leq$ $R e \leq 10^{6}$.

Sundar et al., [7] correlation is:

$$
N u=0.02172 \operatorname{Re}^{0.8} \operatorname{Pr}^{0.5}(1+\phi)^{0.5181}
$$

This correlation has been confirmed experimentally for $\mathrm{Fe}_{3} \mathrm{O}_{4}$-water flow inside circular tube and it is valid in the range of $3000 \leq R e \leq 22000,0 \leq \phi \leq 0.6 \%$, and $3.72 \leq \operatorname{Pr} \leq 6.50$.

Moraveji and Hejazian [6] correlation is:

$$
N u=0.00248 \operatorname{Re}^{1.03} \operatorname{Pr}^{0.5}(1+\phi)^{47.5}
$$

This correlation has been approved numerically for $\mathrm{Fe}_{3} \mathrm{O}_{4}$-water flow inside circular tube and it is valid in the range of $3000 \leq R e \leq 22000,0 \leq \phi \leq 0.6 \%$, and $3.72 \leq \operatorname{Pr} \leq 6.50$.

The friction factor is function of Reynolds number and the channel wall condition. It is low for smooth wall and increases with increasing surface roughness. The experimental correlation for friction factor as follows [7]:

$f=0.349 R e^{-0.25}(1+\phi)^{0.1517}$

A numerical correlation for friction factor is [6]:

$f=0.33139 R e^{-0.25}(1+\phi)^{1.38}$

\subsection{Thermophysical Properties}

In order to simulate nanofluid, effective properties must be calculated first. In this study nanoparticle being considered is magnetic nanoparticles $\mathrm{Fe}_{3} \mathrm{O}_{4}$. Required properties for simulation are effective thermal conductivity $\left(k_{e f f}\right)$, effective dynamic viscosity $\left(\mu_{e f f}\right)$, effective mass $\operatorname{density}\left(\rho_{\text {eff }}\right)$, and the effective specific heat $\left(C_{\text {peff }}\right)$.

The density of nanofluids can be obtained from following equation [26]:

$\rho_{n f}=(1-\phi) \rho_{f}+\phi \rho_{n p}$

where $\rho_{\mathrm{f}}$ and $\rho_{\mathrm{np}}$ are mass densities of base fluid and nanoparticles, respectively.

Heat Capacity is calculated using following equation:

$\left(\rho C_{p}\right)_{n f}=(1-\phi)\left(\rho C_{p}\right)_{f}+\phi\left(\rho C_{p}\right)_{n p}$

where $\left(\rho C_{p}\right)_{f}$ and $\left(\rho C_{p}\right)_{n p}$ are heat capacities of base fluid and nanoparticles, respectively.

Effective thermal conductivity for $\mathrm{Fe}_{3} \mathrm{O}_{4}$ nanofluid is [27]:

$k_{n f}=k_{f}(1+10.5 \varphi)^{0.1051}$ 
where $0 \leq \varphi \leq 2 \%$ and $20 C^{\circ} \leq T \leq 60 C^{\circ}$.

Eq. (24) predicts the thermal conductivity of nanofluids with the effect of temperature by simply substituting the base fluid thermal conductivity at that particular temperature [27].

$\mu_{n f}=\mu_{f}\left(1+\frac{\varphi}{12.5}\right)^{6.356}$

Eq. (25) is used to estimate the effective viscosity of nanofluid with influence of temperature by simply substituting the base fluid viscosity at a particular temperature.

\section{Results}

\subsection{Code Validation}

The three-dimensional channel simulations were performed to analyse the heat transfer rate and fluid flow through different geometries which are square, circular and triangular of straight channels using magnetite nanofluid with different volume fraction. A careful check for the grid independence of the numerical solution has been made to ensure the accuracy and validity of numerical scheme. For this purpose, grid densities $151 \times 41 \times 41,181 \times 61 \times 61$ and $151 \times 61 \times 61$ have been tested for square channel and the results for these cases were compared. The differences between these cases are negligible. So, in viewing of saving the computation time a grid if $151 \times 61 \times 61$ (151 nodes in length and 61 nodes in height in width) were adopted in computations. Same independence study was done for circular tube and triangular duct, for circular duct the grid system is $20 \times 24 \times 400$ along the radial, tangential and axial direction respectively and for triangular duct ( 61 for the three sides of triangle and 180 for the extension).

In order to demonstrate the validity and also precision of the model as well as numerical procedure, the friction factor for square channel was calculated and compared with the experimental correlation by Sundar et al., [7] which is presented as Eq. (20) and numerical correlation by Moraveji and Hejazian [6] which is presented as Eq. (21). Figure 2 shows the correlations results between experimental [7] and numerical correlation [6] with present numerical results.

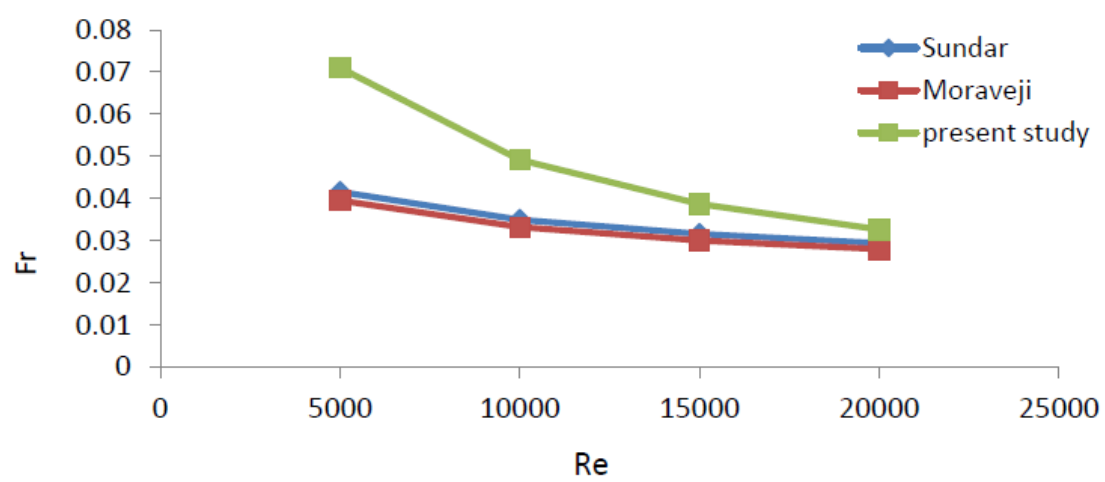

Fig. 2. Comparison between experimental correlation [7] and numerical correlation [6] with present numerical result for $0.2 \%$ volume fraction in turbulent regime in square channel

This is the result of $0.2 \%$ volume fraction in turbulent regime in square channel. As can be seen from Figure 2, the friction factor decreases as Reynolds number increase. Only the result for the $0.2 \%$ volume fraction is shown in the figure, but similar results are obtained for the cases of $0.4 \%$ and $0.6 \%$ of volume fraction. 


\subsection{The Effect of Changing the Cross Section of the Channel}

Figures 3 to 5 show that comparison between three different geometries in terms of Nusselt number at different volume fraction which are $0.2 \%, 0.4 \%$ and $0.6 \%$. The value of average Nusselt number for circular tube are higher compared to the value of average Nusselt number for square and triangular channel. It is worth noting that the circular tube is better than square and triangular channels in terms of Nusselt number.

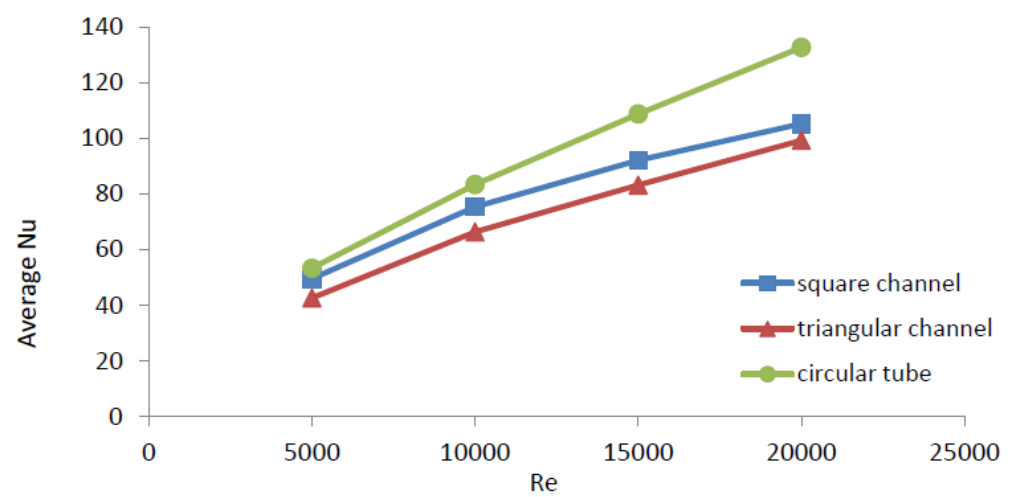

Fig. 3. Comparison between three different geometries in terms of Nusselt number at $0.2 \%$ volume fraction

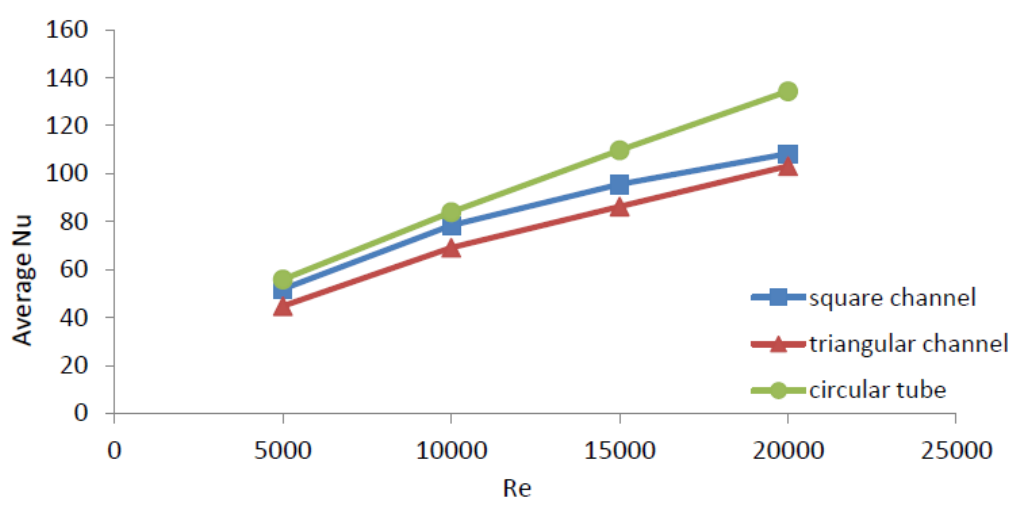

Fig. 4. Comparison between three different geometries in terms of Nusselt number at $0.4 \%$ volume fraction

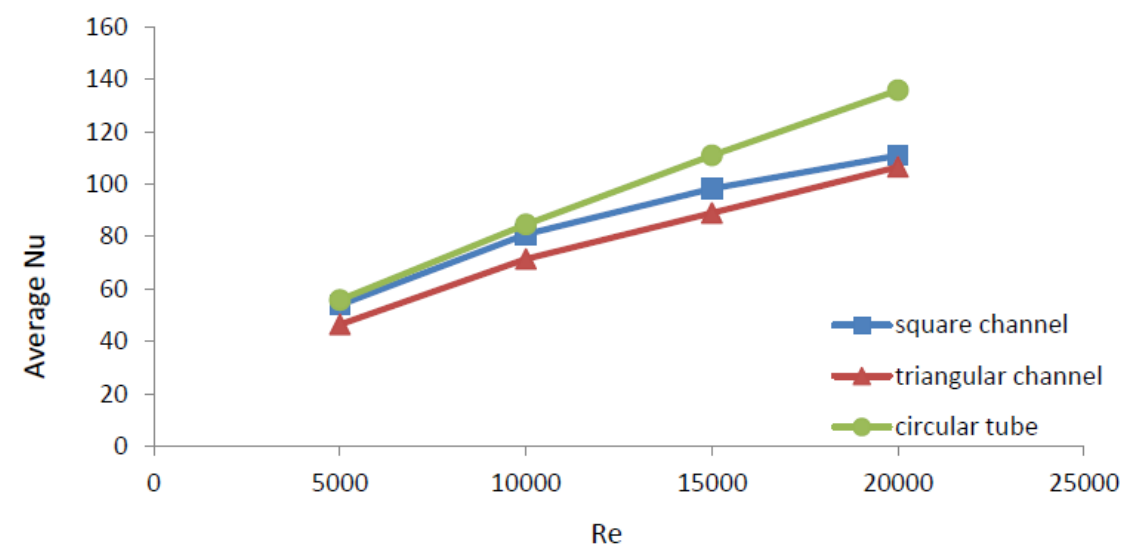

Fig. 5. Comparison between three different geometries in terms of Nusselt number at $0.6 \%$ volume fraction 
Figures 6 to 8 show that comparison between three different geometries in terms of Friction factor at different volume fraction which are $0.2 \%, 0.4 \%$ and $0.6 \%$. As can be seen from the figures, the losses in flow in terms of friction factor is less for circular tube compared to square and triangular channels and the results for three geometries are slightly close at Reynolds number equal to 20000.

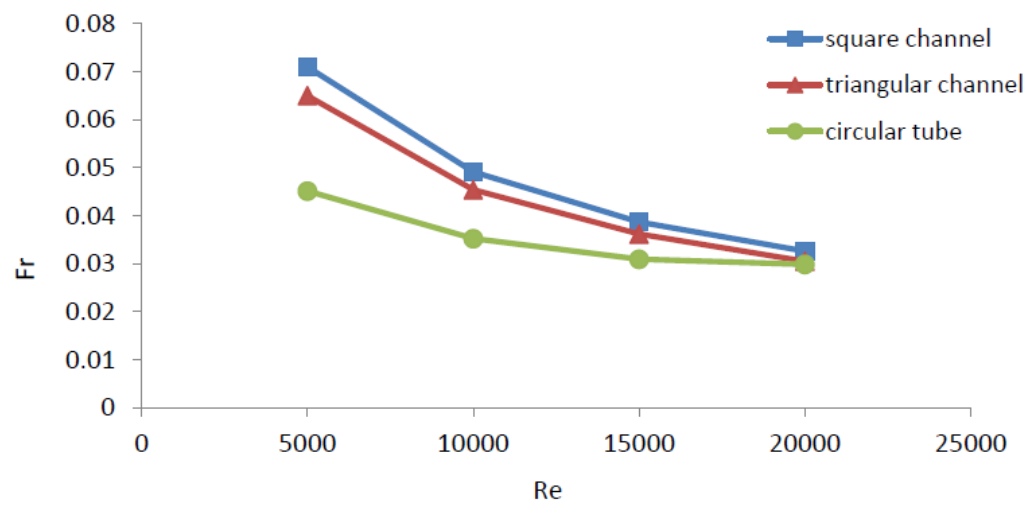

Fig. 6. Comparison between three different geometries in terms of Friction number at $0.2 \%$ volume fraction

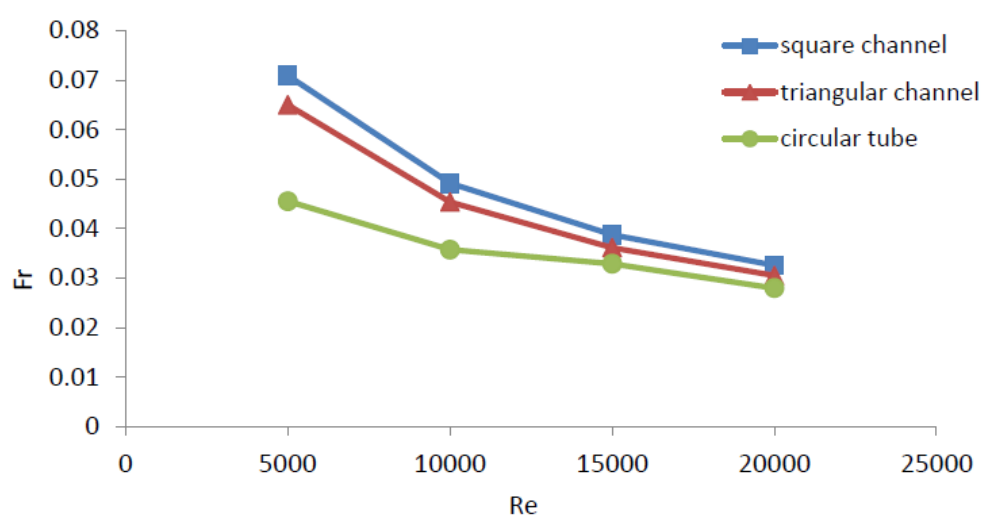

Fig. 7. Comparison between three different geometries in terms of Friction number at $0.4 \%$ volume fraction

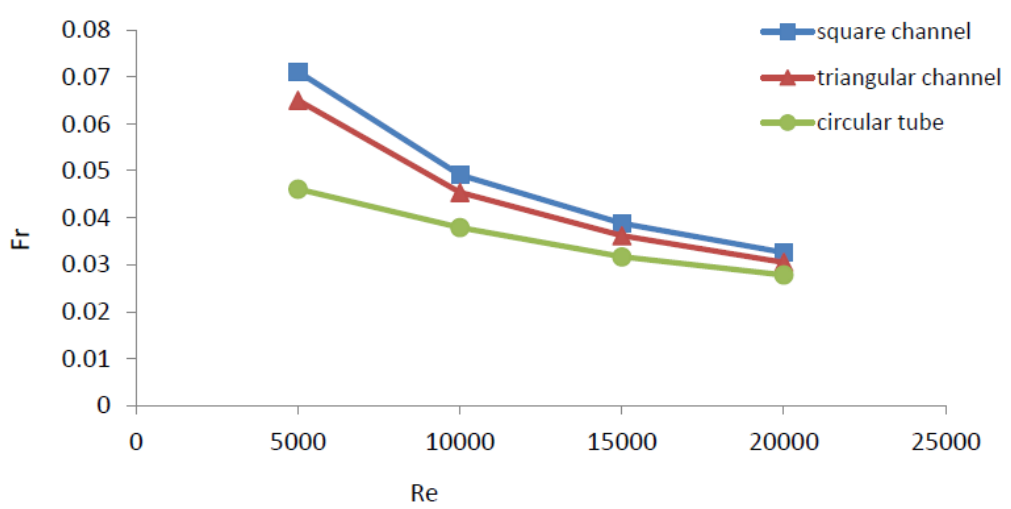

Fig. 8. Comparison between three different geometries in terms of Friction number at $0.6 \%$ volume fraction 


\section{Conclusions}

The turbulent convective heat transfer in 3-dimensional square, circular and triangular straight channels with the range of Reynolds number (5000 to 20000) was numerically investigated. The code validation for enhanced and smooth channel of previous study as maintained in literature review was presented. The results of numerical study were presented in terms of average Nusselt number and friction factor. The turbulent convective of magnetic nanofluids for $\mathrm{Fe}_{3} \mathrm{O}_{4}$-water was presented. The following conclusions were obtained.

I. As the Reynolds number increase the heat transfer rate and Nusselt number increase.

II. As volume fraction increase, the Nusselt number increase compared with water as a coolant.

III. The results revealed that the heat transfer rate is better in circular tube rather than the square and triangular channels.

IV. Friction factor in circular tube is less than that in square and triangular channels.

V. Three correlations were obtained to predict Nusselt number in circular tube and square and triangular channel.

\section{Acknowledgement}

Authors would like to acknowledge Takasago Thermal Engineering Ltd and Universiti Teknologi Malaysia (Grant no. 4B314) for supporting this research activity.

\section{References}

[1] Rostamani, M., S. F. Hosseinizadeh, M. Gorji, and J. M. Khodadadi. "Numerical study of turbulent forced convection flow of nanofluids in a long horizontal duct considering variable properties." International Communications in Heat and Mass Transfer 37, no. 10 (2010): 1426-1431.

https://doi.org/10.1016/i.icheatmasstransfer.2010.08.007

[2] Xuan, Yimin, and Qiang Li. "Investigation on convective heat transfer and flow features of nanofluids." J. Heat transfer 125, no. 1 (2003): 151-155.

https://doi.org/10.1115/1.1532008

[3] Tsai, C. Y., H. T. Chien, P. P. Ding, B. Chan, Tien Yau Luh, and P. H. Chen. "Effect of structural character of gold nanoparticles in nanofluid on heat pipe thermal performance." Materials Letters 58, no. 9 (2004): 1461-1465. https://doi.org/10.1016/i.matlet.2003.10.009

[4] Maïga, Sidi El Bécaye, Cong Tam Nguyen, Nicolas Galanis, and Gilles Roy. "Heat transfer behaviours of nanofluids in a uniformly heated tube." Superlattices and Microstructures 35, no. 3-6 (2004): 543-557. https://doi.org/10.1016/j.spmi.2003.09.012

[5] Sajadi, A. R., and M. H. Kazemi. "Investigation of turbulent convective heat transfer and pressure drop of TiO2/water nanofluid in circular tube." International Communications in Heat and Mass Transfer 38, no. 10 (2011): 1474-1478.

https://doi.org/10.1016/i.icheatmasstransfer.2011.07.007

[6] Moraveji, Mostafa Keshavarz, and Majid Hejazian. "Modeling of turbulent forced convective heat transfer and friction factor in a tube for Fe3O4 magnetic nanofluid with computational fluid dynamics." International Communications in Heat and Mass Transfer 39, no. 8 (2012): 1293-1296. https://doi.org/10.1016/j.icheatmasstransfer.2012.07.003

[7] Sundar, L. Syam, M. T. Naik, K. V. Sharma, M. K. Singh, and T. Ch Siva Reddy. "Experimental investigation of forced convection heat transfer and friction factor in a tube with Fe304 magnetic nanofluid." Experimental Thermal and Fluid Science 37 (2012): 65-71. https://doi.org/10.1016/i.expthermflusci.2011.10.004

[8] Abubakar, Saidu Bello, Nor Azwadi Che Sidik, and Siti Nurul Akmal Yusof. "Measurement of Fluid Flow and Heat Transfer Performance in Rectangular Microchannel using Pure Water and Fe304-H2O Nanofluid." Journal of Advanced Research in Materials Science 65, no. 1 (2020): 1-15. https://doi.org/10.37934/aram.68.1.921 
[9] Khdher, Abdolbaqi Mohammed, Nor Azwadi Che Sidik, Siti Nurul Akmal Yusof, and M'hamed Beriache. "Heat Transfer Enhancement in Straight Channel with Nanofluid In Fully Developed Turbulent Flow." Journal of Advanced Research in Applied Mechanics 63, no. 1 (2019) 1-15.

[10] Choi, Stephen US, and Jeffrey A. Eastman. Enhancing thermal conductivity of fluids with nanoparticles. No. ANL/MSD/CP-84938; CONF-951135-29. Argonne National Lab., IL (United States), 1995.

[11] Lai, W. Y., B. Duculescu, P. E. Phelan, and R. S. Prasher. "Convective heat transfer with nanofluids in a single 1.02mm tube." In ASME 2006 International Mechanical Engineering Congress and Exposition, pp. 337-342. American Society of Mechanical Engineers Digital Collection, 2006.

https://doi.org/10.1115/IMECE2006-14132

[12] Xuan, Yimin, and Qiang Li. "Investigation on convective heat transfer and flow features of nanofluids." J. Heat transfer 125, no. 1 (2003): 151-155.

[13] Li, Qiang, Yi-Min Xuan, Jun Jiang, and Ji-Wan Xu. "Experimental investigation on flow and convective heat transfer feature of a nanofluid for aerospace thermal management." Yuhang Xuebao/Journal of Astronautics(China) 26, no. 4 (2005): 391-394.

[14] Heris, S. Zeinali, S. Gh Etemad, and M. Nasr Esfahany. "Experimental investigation of oxide nanofluids laminar flow convective heat transfer." International communications in heat and mass transfer 33, no. 4 (2006): 529-535. https://doi.org/10.1016/j.icheatmasstransfer.2006.01.005

[15] Faulkner, Daniel J., David R. Rector, Justin J. Davidson, and Reza Shekarriz. "Enhanced heat transfer through the use of nanofluids in forced convection." In ASME 2004 International Mechanical Engineering Congress and Exposition, pp. 219-224. American Society of Mechanical Engineers Digital Collection, 2004. https://doi.org/10.1115/IMECE2004-62147

[16] Thomson, Joseph John. Notes on recent researches in electricity and magnetism: intended as a sequel to Professor Clerk-Maxwell's Treatise on electricity and magnetism. Clarendon Press, 1893.

[17] Namburu, Praveen K., Debendra K. Das, Krishna M. Tanguturi, and Ravikanth S. Vajjha. "Numerical study of turbulent flow and heat transfer characteristics of nanofluids considering variable properties." International journal of thermal sciences 48, no. 2 (2009): 290. https://doi.org/10.1016/i.ijthermalsci.2008.01.001

[18] Changcharoen, Wayo, and Smith Eiamsa-ard. "Numerical investigation of turbulent heat transfer in channels with detached rib-arrays." Heat Transfer-Asian Research 40, no. 5 (2011): 431-447.

https://doi.org/10.1002/htj.20357

[19] Kamali, R., and Ali Reza Binesh. "The importance of rib shape effects on the local heat transfer and flow friction characteristics of square ducts with ribbed internal surfaces." International Communications in Heat and Mass Transfer 35, no. 8 (2008): 1032-1040. https://doi.org/10.1016/j.icheatmasstransfer.2008.04.012

[20] Markatos, N. C. "The mathematical modelling of turbulent flows." Applied Mathematical Modelling 10, no. 3 (1986): 190-220. https://doi.org/10.1016/0307-904X(86)90045-4

[21] Guide, FLUENT User'S. "Version 6.2. 16, Fluent Inc." (2005).

[22] Petrescu, Stoian, M. Costea, C. Harman, and T. Florea. "Application of the direct method to irreversible Stirling cycles with finite speed." International Journal of Energy Research 26, no. 7 (2002): 589-609. https://doi.org/10.1002/er.806

[23] Eiamsa-ard, Smith, and Pongjet Promvonge. "Numerical study on heat transfer of turbulent channel flow over periodic grooves." International Communications in Heat and Mass Transfer 35, no. 7 (2008): 844-852. https://doi.org/10.1016/j.icheatmasstransfer.2008.03.008

[24] Pak, Bock Choon, and Young I. Cho. "Hydrodynamic and heat transfer study of dispersed fluids with submicron metallic oxide particles." Experimental Heat Transfer an International Journal 11, no. 2 (1998): 151-170. https://doi.org/10.1080/08916159808946559

[25] Qingzhong, X. "Effective-medium theory for two-phase random composites with an interfacial shell." Cailiao Kexue Yu Jishu(Journal of Materials Science \& Technology)(China)(USA) 16 (2000): 367-369.

[26] White, F. M. "Viscous Fluid Flow 2nd edition McGraw-Hill." New York (1991).

[27] Sundar, L. Syam, Manoj K. Singh, and Antonio CM Sousa. "Investigation of thermal conductivity and viscosity of Fe304 nanofluid for heat transfer applications." International communications in heat and mass transfer 44 (2013): 7-14. https://doi.org/10.1016/i.icheatmasstransfer.2013.02.014 